\title{
ACIDENTES VASCULARES CEREBRAIS EMBÓLICOS NA CARDIOPATIA CHAGÁSICA CRÔNICA
}

\author{
ISRAel NusSE NZveig * \\ Bernardo Leo Wajchemberg *** \\ Radi Macruz ****
}

\author{
Antonio Spina França Netrto ${ }^{* *}$ \\ JÚlio Timoner **** \\ Luís Gastão do Sêrro Azur.
}

A embolia cerebral é habitualmente secundária a cardiopatias. As condições que com maior freqüência dão origem a êmbolos são a fibrilação auricular e a trombose mural. A fibrilação auricular, na maioria dos casos, é conseqüência de uma estenose mitral reumática, mas pode ocorrer na miocardiosclerose, na hipertensão arterial, no hipertireoidismo, etc. A trombose mural está geralmente associada ao enfarte do miocárdio, a certas miocardites e à endocardite bacteriana subaguda; nesta são encontráveis, também, vegetações valvulares friáveis.

$\mathrm{Na}$ cardiopatia chagásica a embolia cerebral nunca foi descrita, embora de longa data seja conhecida a freqüência com que se instala a trombose mural nessa cardiopatia, bem como seja freqüente o achado, ao exame necroscópico, de embolias nos pulmões, no baço e nos rins. Dias, Laranja e Nóbrega ${ }^{3}$, em 1945, fazendo revisão crítica da literatura a respeito da doença de Chagas, não citam a possibilidade da ocorrência de acidentes vasculares cerebrais na sua evolução. Ramos e col. ${ }^{5}$ (1949), no seu estudo clínico, e Laranja * (1949), revendo a literatura sôbre a cardiopatia chagásica, não fazem, igualmente, referências à existência dessa complicação. De 1949 até a presente data, nada conseguimos encontrar nesse sentido na literatura.

Apresentaremos as observações de 8 doentes internados no Hospital das Clínicas, com cardiopatia chagásica crônica, em cuja evolução ocorre-

* Assistente voluntário da $2^{a}$ Clínica Médica (Serviço do Prof. Luís V. Décourt) da Fac. Med. da Univ. de São Paulo.

* Assistente voluntário da Clínica Neurológica (Serviço do Prof. Adherbal Tolosa) da Fac. Med. da Univ. de São Paulo.

** Assistente voluntário da $1^{\text {a }}$ Clínica Médica (Serviço do Prof. A. B de Ulhoa Cintra) da Fac. Med. da Univ. de São Paulo.

*** Médicos residentes do Hospital das Clínicas da Fac. Med. da Univ. de São Paulo.

**** Assistente extranumerário da $2^{*}$ Clínica Médica (Serviço do Prof. Luís V. Décourt) da Fac. Med. da Univ. de São Paulo.

Nota dos autores - Agradecemos ao Prof. Ludgero da Cunha Motta, Diretor do Departamento de Anatomia Patológica da Fac. Med. da Univ. de São Paulo, pelos exames necroscópicos dos casos apresentados. 
ram acidentes vasculares cerebrais que parecem ter sido conseqüentes a embolias cerebrais.

\section{OBSERVAÇÖES}

Caso 1 - J. M. N. (reg. H.C. 134082), com 33 anos, pardo, casado, brasileiro, lavrador, procedente de Guaianases. Internado no Pronto Socorro em 68-1949. Anamnese: Há 2 anos começou a apresentar sensação de plenitude gástrica, que aumentava com os esforços, dispnéia de esfôrço cada vez mais acentuada e dispnéia paroxística noturna. Ulteriormente, notou aparecimento de edema dos membros inferiores, que se foi generalizando. Em janeiro de 1948 apresentava dispnéia de decúbito e estava em anasarca. Nesse mês manifestou-se bruscamente uma paralisia na metade esquerda do corpo. Medicado, a paralisia foi regredindo, até desaparecer por completo. Em junho de 1948 teve dor súbita, em pontada, no tórax, com escarro hemoptôico, sensação de febre e sudorese intensa. Êsse quadro se repetiu mais duas vêzes. Seis dias antes da internação, após o almôço, foi acometido de fortes tonturas, caindo ao solo, sem perder a consciência. Removido para o leito, notou perda de movimentação da metade esquerda do corpo e incontinência urinária. Dos antecedentes, o único fato de importância é que, há 11 anos, morou no interior de Minas Gerais, em casa de pau-a-pique infestada por "chupanças", tendo sido picado inúmeras vêzes.

Exame clínico - Estado geral mau. Decúbito elevado. Edema generalizado, inclusive do rosto, mais acentuado na metade esquerda do corpo. Pulso, 100 bat./ min; respiração $28 \mathrm{mov} . / \mathrm{min}$; pressão arterial $110-86 \mathrm{~mm} \mathrm{Hg}$; temperatura $37,3^{\circ} \mathrm{C}$. $O$ exame dos diversos aparelhos revelou: no aparêlho respiratório, sinais de derrame pleural na base direita e estertôres subcrepitantes em ambas as bases; no aparêlho circulatório, choque da ponta no $5^{\circ}$ intercosto a um dedo para fora da linha hemiclavicular, e extrassistolia. Sistema nervoso: paciente consciente, com hemiplegia flácida à esquerda.

Exames complementares - Reações de W'assermann e Kehn no sangue negativas. Liqüiido cefalorraquidiano normal, inclusive a pressão (exame realizado em duas ocasiões). Lréia no sangue, $21 \mathrm{mg}$ por $100 \mathrm{ml}$. Proteinas no sangue (em $\mathrm{mg} / 100 \mathrm{ml})$ : totais 6,4 ; albumina 3,6 ; globulinas 2,8 ; relação $\Lambda / \mathrm{G}=1,3$. Urina: ausência de albumina, urobilinogênio até $1: 200$; duas hemácias por campo. Bilirrubinemia (em $\mathrm{mg} / 100 \mathrm{ml}$ ): direta 1,$0 ;$ indireta 0,8. Hemograma: hemácias 3.900 .000 por $\mathrm{mm}^{3}$; hemoglobina $78 \%$; leucócitos 9.000 por $\mathrm{mm}^{3}$; desvio à esquerda. Reação de Machado-Guerrero positiva. Radioscopia do tórax: aumento global da área cardíaca, sobretudo à custa do ventrículo esquerdo; derrame pleural à direita; condensação pequena de limites imprecisos no campo pulmonar inferior esquerdo (enfarte?). Eletrocardiograma: $P$ positiva, de voltagem normal nas 3 derivações; PR regular; QRS de voltagem normal, com espessamentos patológicos; RS-T sem desnivelamentos; $T$ positiva e de baixa voltagem nas 3 derivações; ritmo sinusal; freqüência de 85 bat./min; eixo elétrico com desvio para a esquerda $(P=0,08 ; P R=0,16 ; Q R S=0,12)$. Unipolares de membros: coração em posição elétrica horizontal. $R$ entalhado em aVe. Precordiais: onda de despolarização ventricular do tipo $\mathrm{rsR}$ em $V_{1}$, rS em $V_{3}$, qRs em $V_{5}$. Atraso da deflexão intrínseca em $V_{1}, V_{3}$ e $V_{5}$. RS-T sem desnivelamentos. $T$ i negativa em $V_{1}$ e $V_{3}$, difásica $(-+)^{1}$ em $V_{5}$. ${ }^{5}$ ECG: QRS espessada. $T$ de baixa voltagem, negativa em $V_{3}$. $R$ entalhada em aVe e espessada em $V_{5}$. Desvio do eixo para a esquerda. Posição horizontal. Bloqueio de ramo indeterminado. Conclusão: ritmo sinusal; bloqueio de ramo indeterminado; sinais de comprometimento do miocá rdio.

Evolução e tratamento - Medicado com cardiotônicos e cloridrato de papaverina por via intramuscular, o paciente foi melhorando paulatinamente, tanto da 
hemiplegia como da insuficiência cardíaca. Teve alta em 13-9-1949, compensado e com discreta hemiparesia esquerda.

Comentários - Paciente com 33 anos de idade, com cardiopatia chagásica comprovada, que apresentou dois acidentes vasculares cerebrais, o primeiro há um ano, e o segundo, atualmente, ambos determinando hemiplegia esquerda, nas duas ocasiões na vigência da insuficiência cardíaca congestiva. $O$ paciente teve três enfartes do pulmão, o último precedendo de pouco o segundo icto. Não foram encontradas evidências clínicas de hipertensão arterial ou de arteriosclerose; a negatividade das reações para sífilis tanto no sangue como no líquor afastam a lues como agente etiológico. A evolução parece afastar a possibilidade de um tumor intracraniano. Não se manifestou durante o período de internação qualquer tipo de fibrilação auricular. Não havia passado suspeito, nem foram encontrados sinais clínicos de cardiopatia reumática. A prova de falcização das hemácias para verificar a existência de anemia falciforme, capaz de determinar acidentes vasculares cerebrais, não foi feita porque o hemograma não evidenciou alterações da forma ou do tamanho das hemácias.

Caso 2 - M. J. M. (reg. H.C. 243113), com 33 anos, preta, brasileira, casada, procedente de Itaquaquecetuba. Ultima internação no Hospital das Clínicas em 11-8-1952. Anamnese: Internada pela primeira vez um ano antes, relatando que, há 13 meses, no decorrer do primeiro mês da $9^{9}$ gestação, começou a ap̣resentar dispnéia aos esforços, palpitações rítmicas e necessidade de elevar o decúbito no leito; no $6^{\circ}$ mês da gestação surgiram também edemas dos membros inferiores. $O$ quadro melhorou 8 dias antes do parto, tendo a melhora persistido nos 3 meses subseqüentes. Há um mês surgiu dor em pontada no hemitérax direito, irradiando-se para o dorso, com tosse, expectoração hemoptôica, febre e calafrios. Alguns dias após retornaram a dispnéia e o edema. Este era mais intenso na perna esquerda, sendo quente e doloroso, apresentando-se a pele avermelhada em certas áreas. A paciente nasceu em Minas Gerais e residiu em casa de pau-a-pique, não conhecendo o "chupança".

Exame clinico - Pulso $95 \mathrm{bat} . / \mathrm{min}$; pressão arterial $90-60 \mathrm{~mm} \mathrm{Hg}$; temperatura $36^{\circ} \mathrm{C}$; estertôres de base; choque da ponta no $5^{\circ}$ intercosto direito ao nível da linha axilar anterior; taquicardia; extrassístoles isoladas; sôpro sistólico suave no foco mitral; edema dos membros inferiores. Medicada com cardiotônicas, penicilina e dieta acloretada; a paciente teve alta melhorada em 3-10-1951, com os seguintes diagnósticos: "Dextrocardia. Miocardiopatia crônica. Enfarte do pulmão. Tromboflebite do membro inferior esquerdo".

A paciente passou bem durante alguns dias, mas depois reapareceu, nos pés, o edema, que foi aumentando, e dispnéia progressiva. O quadro foi-se agravando e, em fevereiro de 1952, surgiu tosse com expectoração, de início esbranquiçada e ulteriormente hemoptôica, acompanhada de dôres em pontada na base de ambos os hemitórax, intensificando-se à inspiração. Foi reinternada em 19-2-1952, verificando-se estar o membro inferior direito mais edemaciado que o esquerdo, com edema quente $\mathrm{e}$ doloroso à pressão; além disso, apresentava estertôres de base, extrassistolia, ritmo de galope e fígado a 5 dedos do rebordo costal esquerdo. Medicada como na primeira internação, teve alta melhorada a 2-4-1952.

Em 10-4-1952, a paciente teve dor intensa, súbita e em queimação, no pé esquerdo, irradiando-se para cima até o joelho. Alguns dias depois o pé direito foi atingido pela mesma dor, tornando-se arroxeado $e$ frio. Com o passar dos dias a coloração rôxa foi subindo até alcançar o têrço superior da perna. Ao mesmo tempo surgiu mancha rôxa no têrço inferior da côxa direita. Foi reinternada em 1-5-1952. O exame evidenciava côr arroxeada do pé direito até o têrço superior da perna, com mumificação dos artelhos e faixa arroxeada no têrço superior da côxa direita, face interna. As partes arroxeadas se mostravam frias e dolorosas. $O$ membro inferior esquerdo nada revelava de anormal. Apesar do 
tratamento conservador intensivo, incluindo infiltrações paravertebrais, a paciente não melhorou, tendo sofrido amputação ao nível do têrço superior da côxa cireita. Reinternada em 11-8-1952 porque 15 dias antes surgiram novamente dispnéia e edema do membro inferior esquerdo, a paciente apresentara 8 dias antes desta internação crises generalizadas, mais nítidas na metade esquerda do corpo, tendo-se tornado afásica; há 3 dias perdera a consciência. $\mathrm{Na}$ ocasião da internação a paciente achava-se inconsciente, tendo tido duas crises convulsivas no decorrer do exame; pulso $96 \mathrm{bat} . / \mathrm{min}$; pressão arterial $100-60 \mathrm{~mm} \mathrm{Hg}$; temperatura $36,5 \circ$; respiração $22 \mathrm{mov} . / \mathrm{min}$; edema do membro inferior esquerdo e do côto à direita; raras extrassístoles; fígado a um dedo do rebordo costal esquerdo; hemiparesia esquerda flácida, completa e proporcionada. Óbito 4 dias anós a reinternação.

Exames complementares - Reação de Machado-Guerrero: positiva, em titulo superior a 3,3. Liqüido cefalorraquidiano: punção suboccipital; pressão inicial 39; líquor levemente hemorrágico (após centrifugação, líquor límpido e xantocrômico); 3 células por $\mathrm{mm}^{3}$ (linfócitos $64 \%$, monócitos $24 \%$ e neutrófilos $12 \%$ ); hemácias 3666,6 por $\mathrm{mm}^{3}$, parcialmente degeneradas; proteínas $0,40 \mathrm{~g} / \mathrm{l}$; cloretos $7 \mathrm{~g} / \mathrm{l}$; glicose $0,90 \mathrm{~g} / \mathrm{l}$; r. Pandy e Nonne-Appelt positivas; r. Takata-Ara fortemente positiva (tipo misto); r. Wassermann, Steinfeld, Eagle e para cisticercose negativas. Reações de Wassermann, Kahn e Kline no sangue. negativas. Hemourama: hemácias 4.310.000 por $\mathrm{mm}^{3}$; leucócitos 11.800 por $\mathrm{mm}^{3}$; hemoglobina 13,6 $\mathrm{g} / 100 \mathrm{ml}(85 \%)$; valor globular 0,9 ; neutrófilos $83 \%$ (bastonetes $8 \%$, segmentados $75 \%$ ), linfócitos $16 \%$, monócitos $1 \%$; granulações tóxicas nos neutrófilos. $R a$ diografias do tórax: dextrocardia; aumento pronunciado da área cardíaca, com predominância do ventrículo esquerdo. Eletrocardiograma: ritmo sinusal, com 100 bat./min; forte desvio do eixo elétrico de $\mathrm{P}$ para a direita; onda $\mathrm{P}$ de amplitude e voltagem normais (negativa em $D_{1}$ e $D_{2}$, aVe e $V_{3}$, e positiva em aVr); QRS de extrema baixa voltagem nas derivações clássicas e unipolares dos membros em $\mathrm{V}_{3}$ e $\mathrm{V}_{5}$; a onda $\mathrm{R}$ diminui de amplitude nas precordiais da direita para a esquerda. Conclusão: curva de dextrocardia, com sinais de comprometimento difuso do miocárdio.

Exame necroscópico -- Miocardite crônica chagásica. Situs inversus cordis. Hipertrofia e dilatação globais. Grande trombo mural no ventrículo esquerdo. Trombose da aorta abdominal e de ambas as ilíacas. Situs inversus da aorta e das vísceras abdominais. Enfarte anêmico do pâncreas e do rim direito. Edema e congestão do encéfalo, com arteriosclerose do tipo difuso. Ao corte, 3 áreas de amolecimento hemorrágico, duas delas nos lobos frontais e outra no lobo occipital direito; êstes focos de amolecimento encontram-se próximo às meninges.

Comentários - Paciente de 33 anos de idade, com cardiopatia chagásica crônica comprovada, em insuficiência cardíaca congestiva. Na evolução do caso verificaram-se vários enfartes pulmonares, provàvelmente em conseqüência, não só da estase acentuada, como talvez de embolias partidas da tromboflebite dos membros inferiores. A paciente apresentou, ainda, um quadro de oclusão arterial para o lado do membro inferior direito, que evoluiu para a gangrena, tornando nccessária a amputação. Finalmente, sof reu um acidente vascular cerebral, acomipanhado de crises convulsivas, com hemiparesia esquerda, vindo a falecer. $O$ exame necroscópico revelou, além da miocardite chagásica, a existência de grande trombo mural na parede do ventrículo esquerdo, trombose da aorta abdominal e das artérias ilíacas, enfartes anêmicos do pâncreas e do rim direito e, por fim, três áreas de amolecimento hemorrágico no encéfalo. As artérias do encéfalo apresentavam arteriosclerose do tipo difuso, sem sinais dêsse processo em qualquer outro órgão. Os enfartes pancreático e renal são, certamente, decorrentes de embolias partidas do trombo mural cardíaco. Quer-nos parecer que, na ausência de arteriosclerose ou de processo inflamatório local, a trombose da aorta e das ilíacas também se tenha iniciado por uma embolia, sendo o êmbolo proveniente do trom- 
bo mural. A multiplicidade de embolias sugere que os amolecimentos cerebrais tenham tido a mesma etiologia, motivo pelo qual esta paciente foi incluída no presente trabalho, embora o encontro de arteriosclerose cerebral não permita afastar fenômenos de trombose de etiologia arteriosclerótica. Merece reparo o achado dessa arteriosclerose cerebral isolada em indivíduo relativamente jovem. A dexirocardia que a paciente apresentava em nada poderia favorecer ou determinar a eclosão do acidente vascular cerebral.

Caso 3 - A. J. S. (reg. H.C. 268686), com 45 anos, branco, brasileiro, lavrador. Internado em 9-7-1952. Anamnese: Há 9 meses, dispnéia aos esforços que se acentuou progressivamente. Há 4 meses, dôres torácicas e tosse com expectoração hemoptôica. Nos últimos meses surgiu, nos membros inferiores, edema frio, mole, indolor e depressível, de caráter vespertino. Quatro horas antes de ser hospitalizado perdeu bruscamente a consciência e quando voltou a si notou que tinha perdido o contrôle da metade esquerda do corpo. Já morou em casa de pau-a-pique, infestada por "chupanças", tendo sido picado.

Exame clínico - Estado geral regular, decúbito elevado; dispnéia. Pulso 110 bat./min, arrítmico; respiração 36 bat./min; pressão arterial $135-90 \mathrm{~mm} \mathrm{Hg}$; temperatura $36 \circ \mathrm{C}$. Estase jugular bihateral. Aparêlho respiratório: alguns roncos esparsos; estertôres subcrepitantes finos nas bases. Aparêlho circulatório: bulhas abafadas; numerosas extrassístołes por minuto. Abdome: fígado a 2 dedos do rebordo costal. Sistema nervoso: hemiplegia esquerda, completa e proporcionada, flácida.

Exames complementares --- Urina normal. Uréia no sangue: $40 \mathrm{mg} / 100 \mathrm{ml}$. 'T'empo de coagulação, 6 minutos; tempo de sangria, 2 minutos. Liqüido cefalorraquidiano normal. Reação de Machado-Guerrero positiva (título não calculado; sôro anti-complementar).

Evolução e tratamento - O paciente foi medicado com cardiovitol, glicose hipertônica, cloridrato de papaverina, oxigênio e dieta de arroz, melhorando no que se referia às perturbações cardíacas. A hemiplegia esquerda também regrediu progressivamente, permanecendo paresia no membro superior. Nessas condições, o paciente teve alta 15 dias depois, sendo reinternado em 31-12-1952, com cardiopatia novamente descompensada, porém com o quadiro neurológico em regressão quase completa. Teve alta após 10 dias.

Comentários - Paciente de 45 anos de idade, com cardiopatia crônica chagásica comprovada, em insuficiência cardíaca congestiva. Apresentou um enfarte pulmonar e, alguns meses depois, um acidente vascular cerebral com hemiplegia esquerda, de evolução favorável. Ao exame físico, nunca se encontrou fibrilação auricular. Não havia sinais clínicos de cardiopatia reumática, nem de endocardite bacteriana subaguda. O exame liquórico não revelou sinais de lues nervosa. A anemia falciforme não deve ser lembrada por ser o doente de côr branca. $O$ quadro clínico parece coadunar-se com hipótese de embolia cerebral partida do trombo mural cardíaco. Levando-se em conta a idade do paciente e o encontro de níveis de pressão arterial um pouco elevados nos primeiros dias de internação, não se poderia afastar completamente a hipótese de doença vascular hipertensiva, associada a arteriosclerose, com trombose cerebral. Acreditamos, porém, que a interferência do quadro cardíaco seja mais provável.

Caso 4 - E. P. S. (reg. H.C. 92273), com 23 anos, preta, brasileira, casada, cozinheira, procedente da Capital. Cltima internação no Pronto Socorro em 187-1953. Anamnese: Foi internada pela primeira vez no Pronto Socorro em 1952 por apresentar insuficiência cardíaca congestiva que há um mês se instalava progressivamente; teve alta melhorada. Após a alta, embora tomasse cardiotônicos, piorou ràpidamente, sendo atendida no Pronto Socorro 6 dias após, intensamente 
dispnêica, com taquicardia, ritmo de galope e edema dos membros inferiores, referindo dôres de tipo pleural na base do hemitórax direito e tosse com escarro hemoptôico. Seis dias depois, achando-se melhor, repentinamente deixou de falar e de mover os membros superior e inferior direitos, sem perder a consciência; foi reinternada em 12-9-1952. Morou em casa de pau-a-pique, onde foi picada por "chupança".

Nessa ocasião o exame físico mostrava um estado geral regular; dispnéia com decúbito elevado; edema dos membros inferiores e superiores e da parede abdominal; estase jugular bilateral; pulso 100 bat./min, rítmico; respiração 20 mov./ min; pressão arterial $120-80 \mathrm{~mm} \mathrm{Hg}$; temperatura $36 \circ \mathrm{C}$. No aparêlho respiritório havia alguns estertôres subcrepitantes nas bases; no aparêlho circulatório, taquicardia, fases de bigeminismo, ritmo de galope; no abdome, fígado a uin dedo, baço não percutível. Para o lado do sistema nervoso foi encontrada heniplegia flácida à direita, completa e proporcionada, e afasia. Foi medicada com digitalina, Esidron, oxigênio e dieta acloretada. A insuficiência cardíaca melhorou ràpidamente. Houve regressão parcial da afasia 3 dias depois. A hemiplegia regrediu parcialmente. Alta a 28-11-1952, compensada, com déficit motor no hemicorpo direito e comprometimento parcial da linguagem.

Exames complementares - Prova de falcização das hemácias negativa. Reação de Machado-Guerrero: positiva em título de 4,2 unidades. Urina normal. Uréia no sangue $21 \mathrm{mg} / 100 \mathrm{ml}$. Reações sorológicas para lues negativas. Liqüido cefalorraquidiano normal. Bilirrubinas no sôro sangüineo $(\mathrm{em} \mathrm{mg} / 100 \mathrm{ml})$ : direta total 0,7; indireta 0,6; total 1,3. Radiografia do tórax: aumento global da área cardíaca, com predominância do ventrículo esquerdo. Eletrencefalograma: ondas lentas, de amplitude maior que a normal, na região frontocentral esquerda. Eletrocardiograma: ritmo sinusal, com 125 bat./min. Coração em posição elétrica semi-horizontal. QRS de tipo $q R$ em $V_{5}$. RS-T minus em $D_{1}, D_{2}$ e $V_{5}$. Onda $T$ difásica em $\mathrm{D}_{1}, \mathrm{D}_{2}$, aCf $\mathrm{e} \mathrm{V}_{5}$. QRS espessado. Conclusão: taquicardia sinusal; sinais sugestivos de hipertrofia ventricular esquerda e perturbação na condução intraventricular.

Evolução - Em 18-7-1953, 18 dias após ter tido alta de uma das enfermarias de Clínica Médica, foi novamente internada no Pronto Socorro; passara hem nos cinco primeiros dias que se seguiram à alta, reaparecendo então dispnéia $\mathrm{e}$ edema (membros inferiores), que aumentaram progressivamente, piorando bastante dois dias antes da internação; não expectorou sangue; urina carregada; vômitos. Exame clínico - Estado geral regular; ortopnéia, edema acentuado dos membros inferiores; estase jugular não perceptível; cianose das extremidades, que se achavam frias; sonolência. Pulso imperceptível. Pressão arterial zero. Respiração $56 \mathrm{mov} . / \mathrm{min}$. Aparêlho respiratório: diminuição da respiração na base direita; estertôres subcrepitantes finos e médios nos dois terços inferiores de ambos os campos pulmonares. Aparêlho circulatório: ritmo de galope, frequiência de 100 bat./min. Abdome: ascite discreta; fígado palpável a 4 dedos do rebordo costal. Sistema nervoso: hemiplegia direita, com reflexos musculares profundos vivos. Obito 4 horas depois de internada.

Exame necroscópico - Edema dos membros superiores e inferiores e da região do pescoço. Hidrotórax bilateral; congestão passiva crônica dos pulmões; enfarte antigo da base do pulmão direito. Hidropericárdio; máculas láteas do pericárdio visceral; dilatação global do coração; discreta hipertrofia do ventrículo direito; tromboses murais do ventrículo esquerdo; miocardite crônica. Ascite. Congestão passiva do fígado; necroses focais. Enfartes bilaterais antigos dos rins. Encéfalo de forma, volume e consistência normais, pesando $1.200 \mathrm{~g}$; amolecinento anêmico antigo do putâmen, cabeça do núcleo caudado e cápsula interna esquerda; artériae de aspecto normal; artéria cerebral média ocluida ao nível ỏos locais de emissão dos seus ramos profundos. 
Comentários - Paciente de 23 anos de idade, com cardiopatia chagásica comprovada, com insuficiência cardíaca congestiva, compensada em várias ocasióes, vindo a falecer em choque cardiogênico. Apresentara enfarte pulmonar e, alguns dias depois, acidente vascular cerebral com hemiplegia direita. Não havia fibrilação auricular nem evidências de cardiopatia reumatismal ou de endocardite bacteriana subaguda. As reações sorológicas e o exame do líquor afastaram a sífilis. A prova de falcização das hemácias negativa excluiu a anemia falciforme. Não se verificou hipertensão arterial.

A paciente faleceu 10 meses após o acidente vascular cerebral, durante novo episódio de insuficiência cardíaca congestiva, estando ainda patente a hemiplegia direita. O exame necroscópico confirmou a existência de insuficiência cardíaca congestiva, com edema generalizado e coleção líqüida nas cavidades serosas. No coração foi verificada a existência de miocardite crônica, não tendo sido possível identificar pelo exame histológico a presença de parasitas; entretanto, a positividade da reação de Machado-Guerrero já é elemento suficiente para sustentar o diagnóstico etiológico. A presença de trombos murais na parede do ventrículo esquerdo e de numerosos enfartes cicatriciais em ambos rins, ao mesmo tempo que a oclusão da artéria cerebral média, oferecem base para sustentar a natureza embólica desta última.

Caso 5 - A. A. O. (reg. H.C. 217991), com 27 anos, preta, csaada, brasileira, prendas, procedente da Capital. Internada no Pronto Socorro em 30-41953. Anamnese: Em janeiro de 1951, começou a apresentar dispnéia e palpitações aos esforços, edema dos membros inferiores, que se intensificava com o correr do dia. Após uma semana, aumento de volume do abdome e dispnéia em repouso. Fêz tratamento médico, tendo melhorado, para algum tempo depois retornarem os sintomas. A urina assumiu coloração escura, em maior volume à noite. O edema se estendeu, entrando em anasarca. Foi internada no Hospital das Clínicas em abril de 1951; tratada com cardiotônicos e diuréticos, teve alta melhorada no mês seguinte. A 27-9-1952 procurou o Pronto Socorro, onde foí internada, apresentando dispnéia intensa, tosse, expectoração hemoptôica, palpitação, dor no hipocôndrio direito e relatando que havia ficado bruscamente con a metade esquerda do corpo paralisada. Mineira, não morou em casa de pau-apique, não conhece o "barbeiro".

Ao exame clínico foi verificado estado geral mau; dispnéia intensa; edema intenso dos membros inferiores; estase jugular bilateral; icterícia das conjuntivas. Pulso: 120 bat./min. Pressão arterial 100-60 mm Hg. Respiração: $36 \mathrm{mov} . / \mathrm{min}$. Temperatura: $\mathbf{3 7}^{\circ} 3^{\circ} \mathrm{C}$. Aparêlho respiratório: estertôres subcrepitantes em ambas as bases; sinais de derrame pleural na base direita. Aparêlho circulatório: taquicardia; ritmo de galope; sôpro sistólico suave no foco mitràl. Abdome: figado a 3 dedos, doloroso à palpação. Sistema nervoso: hemiparesia esquerda. Foì medicada com Digifortis, Esidron e oxigênio. A insuficiência cardíaca compensou-se e a hemiparecia esquerda melhorou ligeiramente, permitindo a marcha, embora com dificuldade. Nessas condições, teve alta a 3-12-1952.

Exames complementares - Proza de falcização das hemácias (repetidas duas vêzes): negativa. Reação de Machado-Guerrero: positiva, com título aproximadamente 3,1. Líqüido cefalorraquidiano normal. Reações sorológicas para sífilis: Wassermann, anticomplementar; Kahn e Kline, negativos. Urina: pigmentos biliares positivos; urobilinogênio positivo até $1: 100$; albumina $0,1 \mathrm{~g} / \mathrm{l}$; substâncias redutoras ausentes; no sedimento, leucócitos 20 por campo, hemácias 3 por campo (430 aumentos). Bilirrubinas no sangue $(\mathrm{em} \mathrm{mg} / 100 \mathrm{ml})$ : direta imediata 2,7, direta total 4, indireta 1,7, total 5,8. Provas de função hepática: TakataAra positiva; formol-gel negativa; Weltmann, coagulação no tubo 5; Hanger positiva; timol 2,3 unidades MacLagan. Eletrocardiograma: Complexo auricular sem alteraçóes, $P R$ regular. QRS apresenta-se com $S$ espessado e alargado em $D_{1}$, $D_{2}$, aVL e $V_{5}$. $Q$ profundo e nítido em $D_{3}$. QRS do tipo $r R$ em $V_{1}$. Com- 
plexo em $\mathrm{M}$ em $\mathrm{V}_{3}$. Duração de QRS $0,12 \mathrm{seg}$. Atraso da deflexão intrinsicóide em $V_{1}$ e $V_{3}$. Extrassístole ventricular isolada em $D_{1}$. RS-T com desnivelamento minus em $V_{1}$ e $V_{3}$. ' $T$ negativa em $V_{1}$ e $V_{3}$ e difásica em $V_{5}$. Conclusão: bloqueio completo do ramo direito do feixe de His.

Paciente reinternada no Pronto Socorro em 30-4-1953, em mau estado geral, incapaz de prestar informações. Dispnêica, edema acentuado dos membros inferiores e do membro superior esquerdo; cianose acentuada das unhas; ictericia das conjuntivas oculares e mucosa bucal. Pulso não palpável. Pressão arterial zero. Afebril. Respiração $30 \mathrm{mov} . / \mathrm{min}$. Estase jugular bilateral acentuada. Estertôres subcrepitantes em ambas as bases. Coração rítmico, com sôpro sistólico suave no foco mitral e hiperfonese da segunda bulha no foco pulmonar. Abdome ahaulado, com sinais de ascite; fígado a 4 dedos, doloroso à palpação. Sistema nervoso: hemiparesia esquerda, reflexos musculares profundos presentes e normais. A paciente foi medicada com Cardiovitol, Teofilina, Esidron, oxigênio e dieta acloretada. Ã noite a pressão arterial havia-se elevado para $100-70 \mathrm{~mm} \mathrm{Hg}$. No segundo e terceiro dia de internação a paciente continuou em mau estado geral, o pulso tornou-se palpável; tosse com expectoração esbranquiçada e vômitos repetidos. A medicação constou de Cardiovitol. No quarto dia o pulso era de 104 bat./min, com raras extrassístoles isoladas e a pressão arterial, $85-70 \mathrm{~mm} \mathrm{Hg}$. Ritmo de galope. A icterícia havia-se acentuado. Dispnéia pouco intensa. Raros estertôres nas bases. Obito às 14 horas.

Exame necroscópico - Edema discreto dos membros inferiores; ictericia das conjuntivas oculares, congestão e edema dos órgãos do pescoço. Hidrotórax bilateral; congestão, edema e arteriosclerose dos pulmões. Hipertrofia e dilatação global do coração; trombose mural da ponta do ventrículo esquerdo; trombose organizada da aurícula direita; lipoidose da aorta. Ascite. Congestão passiva crônica do fígado, com necrose centroglobular. Congestão passiva crônica do baço e dos rins. Gastrite catarral. Colite folicular. $O$ encéfalo se apresentava com forma, volume e consistência normais; não havia arteriosclerose dos vasos da base (deixa de ser apresentado o resultado dos cortes porque foi fixado para exame ulterior, dentro do plano de estudos da doença de Chagas do ponto de vista anátomo-patológico, que está sendo efetuado no Serviço onde foi praticada a necrópsia).

Comentários - Paciente de 27 anos de idade, com cardiopatia chagásica comprovada, que apresentou diversos episódios de insuficiência cardíaca congestiva, vindo a falecer na vigência de um dêles. Apresentou, quase simultâneamente, enfarte pulmonar e acidente vascular cerebral, com hemiparesia esquerda. Não havia fibrilação auricular e a pressão arterial permaneceu dentro dos limites da normalidade. Não se encontraram fenômenos de arteriosclerose, nem sinais clínicos de cardiopatia reumática ou de endocardite bacteriana subaguda. A prova de falcização das hemácias afastou a anemia falciforme. As reações sorológicas e o exame do líquiido cefalorraquidiano excluíram a sífilis. Merecem ser salientadas a positividade da reação de Machado-Guerrero e, na necrópsia, a presença de trombo mural da ponta do ventrículo esquerdo, bem como a ausência de sinais de arteriosclerose dos vasos do encéfalo.

Caso 6 - M. X. S. (reg. HC 295008), com 39 anos, parda, solteira, brasileira, tecelã, procedente de Pirituba. Internada no Pronto Socorro a 9-10-1952. Anamnese: História de cefaléia discreta há 3 anos, de maior intensidade na região frontal direita, com piora há 3 semanas, quando surgiram diarréia $\mathrm{e}$ vômitos, os quais desapareceram espontâneamente. No dia da internação, após o almôço, começou a proferir palavras sem nexo e ao mesmo tempo ficou com a metade esquerda do corpo paralisada. Não perdeu a consciência. Foi então trazida ao Pronto Socorro. Conhece o "chupança", tendo sido picada por êle. 
Exame clínico - Obnubilada; estado geral bom; mucosas coradas. Pulso 80 bat./min; respiração $20 \mathrm{mov} . / \mathrm{min}$; pressão arterial $120-80 \mathrm{~mm} \mathrm{Hg}$; temperatura $35,9 \circ \mathrm{C}$. Aparêlho circulatório: bulhas abafadas em todos os focos; raras extrassístoles isoladas. Sistema nervoso: hemiplegia esquerda completa e proporcionada; desvio conjugado da cabeça e dos olhos para a direita. Demais aparelhos: nada de anormal ao exame.

Evoluçẩo e tratamento - Foi medicada com sôro glicosado hipertônico e analgésicos; a dor na região frontal direita persistiu inalterada. No sexto dia passou a ser medicada com cloridrato de papaverina. Alta a 9-2-1953, movimentando bem o membro inferior esquerdo, enquanto o superior continuava paralisado.

Exames complementares - Reação de Machado-Cłuerrero: positiva. Prova de falcizaçẫo das hemácias (repetida uma vez) negativa. Reações sorológicas para sifilis (Wassermann, Kahn e Kline) negativas. Líquiido cefalorraquidiano: punção suboccipital em posição deitada; pressão inicial $15 \mathrm{~cm}$ de água; pressão fínal 8; líquor límpido e levemente xantocrômico; 1 célula por $\mathrm{mm}^{3} ; 124$ hemácias por $\mathrm{mm}^{3}$ (em degeneração); proteínas $40 \mathrm{mg} / 100 \mathrm{ml}$; cloretos $690 \mathrm{mg} / 100 \mathrm{ml}$; glicose 75 $\mathrm{mg} / 100 \mathrm{ml}$; r. Pandy e Nonne positivas; r. benjoim 01100.12210.00000.0; r. Takata-Ara positiva $(+)$ tipo floculante; r. Wassermann, Steinfeld, Weinberg, Eagle e Meinicke negativas. Fundo de ôlho: papilas de limites, nível e coloração normais; vasos normais. Radiografia do tórax: campos pulmonares normais; coração e vasos da base normais. Eletrocardiograma: Ritmo sinusal com 68 bat./min. Coração em posição elétrica horizontal. QRS espessado. RS-T com desnivelamento minus em $V_{1}$ ' Onda ' $T$ difásica em $V_{1}$, aVL e $V_{5}$, negativa em $V_{3}$. Conclusão: ritmo sinusal normal; alterações de QRS-T indicativas de comprometimento do miocárdio. Eletrencefalograma: ondas $\delta$ na região centro-paríeto-temporal direita. Craniograma: ausência de sinais de hipertensão intracraniana. Angiografia cerebral (carótido-angiografia direita): artérias cerebrais de forma, calibre e trajeto normais (exame efetuado em 10-1-1953).

Comentários - Paciente de 39 anos de idade, com moléstia de Chagas comprovada. Embora o eletrocardiograma revelasse sinais sugestivos de comprometimento do miocárdio, a área cardíaca se apresentava normal ao exame radiológico e, funcionalmente, a insuficiência cardíaca era da classe I. Sofreu acidente vascular cerebral, com hemiplegia esquerda. O exame clínico e os exames subsidiários afastaram a hipertensão arterial, a sífilis, a fibrilação auricular, a cardiopatia reumatismal, a endocardite bacteriana subaguda e a anemia falciforme. Não havia sinais de arteriosclerose. Desta forma, o quadro pôde-se superpor aos dos outros pacientes, embora deva ser ressaltada outra possibilidade. De fato, como o exame liquórico revelou ser o acidente vascular de natureza hemorrágica e a paciente relatava história de cefaléias freqüentes, havia a possibilidade de se tratar de um aneurisma de artéria cerebral com rotura no interior da massa encefálica. A angiografia cerebral não mostrou a presença de anomalias vasculares, o que não basta para excluir tal hipótese.

Caso 7 - M. L. S. (reg. H.C. 314097), com 34 anos, parda, solteira, brasileira, prendas domésticas, procedente do Estado do Paraná. Internada no Pronto Socorro a 23-2-1953. Anamnese: Três mẹses antes de procurar o Hospital, dispnéia de esfôrço, precedida de ligeiro edema dos membros inferiores. A dispnéia e o edema se intensificaram aos poucos, obrigando de início a paciente a reduzir as atividades e, há dois meses, a se acamar. Decúbito elevado e dispnéia paroxística noturna. A urina tornou-se escassa e assumiu coloração escura. Tinha sensação de estufamento no epigastro e por vêzes referia dôres no hipocôndrio direito. Dois dias antes consultou um médico, o qual the prescreveu injeções de Cardiovitol com teofilina. Com tal medicação melhorou, diminuindo a dispnéia e intensificando-se a diurese. $\mathrm{Na}$ madrugada do dia da internação acordou, sùbitamente, agitada, desgovernada, não podendo sentar-se no leito. Estava 
um tanto alheia ao ambiente e se queixava de cefaléia. Nessas condições, foi trazida ao Pronto Socorro. Residiu em zona chagásica, tendo sido picada pelo "chupança”. Malária há dois anos.

Exame clínico - Paciente em mau estado geral, dispnêica e obnubilada; edema da região sacra e dos maléolos; discreta estase jugular bilateral. Pulso 130 bat./min, rítmico; respiração $40 \mathrm{mov} . / \mathrm{min}$; pressão arterial $140-100 \mathrm{~mm} \mathrm{Hg}$; temperatura $35,8^{\circ} \mathrm{C}$. Aparêlho circulatório: choque da ponta no sexto intercosto, um dedo para fora da linha hemiclavicular, difuso; ritmo de galope. Abdome: fígado a 2 dedos, doloroso à palpação. Sistema nervoso: consciente, em decúbito passivo, com hemiplegia flácida esquerda, completa e proporcionada; discreta disartria. Reflexos musculares profundos vivos nos- membros esquerdos, principalmente o patelar, de resposta policinética; reflexos cutâneo-abdominais ausentes à esquerda. Sinal de Babinski no pé esquerdo. Clono da rótula esquerda. Hipoestesia táctil, térmica e dolorosa do hemicorpo esquerdo, predominando na extremidade distal dos membros. Pupilas isocóricas, reagindo à luz. Paralisia facial esquerda do tipo central e desvio da língua para a esquerda.

Exames complementares - Liqüido cefalorraquidiano normal. Prova de falcização das hemúcias (repetida duas vêzes): negativa. Prova de Machado-Guerrero: positiva no sangue, com título 3,7 ; negativa no líquor. Hemograma: hemácias 4.400.000 por $\mathrm{mm}^{3}$; leucócitos 7.200 por $\mathrm{mm}^{3}$; hemoglobina $10,7 \mathrm{~g} / 100 \mathrm{ml}(67 \%)$; valor globular 0,75 ; polimorfonucleares neutrófilos $61 \%$ (bastonetes $4 \%$, segmentados 57\%); polimorfonucleares eosinófilos $2 \%$; linfócitos $34 \%$; monócitos 3\%; aniso e poiquilocitose discretas. Reações sorológicas para sífilis (Wassermann, Kahn e Kline) no sangue negativas. Urina normal. Eletrocardiograma: Onda $\mathbf{P}$ positiva e entalhada em $D_{1}$ e $D_{2}$, negativa em $D_{3}$, difásica em $V_{1}$. PR regular. QRS de voltagem normal, alargado e com espessamentos de $R$ e $S$ nas clássicas. Configuração em $M$ em $V_{1}$ e do tipo $r S$ em $V_{5}$. S-T arqueado em $V_{1}$ e $V_{3}$. Duração: P 0,08 seg; PR 0,17 seg; QRS 0,12 seg. Frequiência: 80 bat. $/ \mathrm{min}$. Arritmia sinusal. Eixo elétrico desviado para a esquerda. Coração em posição clétrica horizontal e em rotação horária. Conclusões: perturbação na condução intraauricular; bloqueio completo do ramo direito. Fundo de ôlho normal.

Evolução e tratamento - A paciente foi tratada com Cardiovitol, teofilina, cloridrato de papaverina e dieta acloretada. A partir do terceiro dia de internação, a pressão arterial se normalizou, mantendo-se nesses níveis nos dias subseqüentes. A insuficiência cardíaca melhorou paulatinamente. O quadro neurológico permaneceu inalterado.

Comentários - Paciente de 34, anos de idade, com cardiopatia chagásica comprovada, em insuficiência cardíaca congestiva. Apresentou acidente vascular cerebral, com hemiplegia esquerda. Clinicamente e pelos exames complementares afastou-se a fibrilação auricular, a cardiopatia reumatismal, a endocardite bacteriana subaguda, a anemia falciforme e a sífilis. Nos dois primeiros dias de internação a pressão arterial se manteve em níveis ligeiramente superiores aos normais; nos dias subseqüentes a pressão se normalizou e não se conseguiu surpreender outros sinais de hipertensão arterial ou de comprometimento renal. Esses fatos, aliados à idade relativamente baixa da paciente, tornam muito pouco provável (embora não de todo impossível) a etiologia hipertensiva dêsse icto.

Caso 8 - M. E. B. (reg. H.C. 302759), com 28 anos, branco, brasileiro, motorista, procedente da Capital. Internado no Pronto Socorro a 27-1-1953. Anumnese: Há 10 meses, começou a apresentar edema dos membros inferiores e dispnéia aos esforços, obrigando-o a abandonar o trabalho. Melhorou com o tratamento, voltando a trabalhar. Passou bem até há 4 meses, quando, ao andar, sentiu tonturas e caiu ao solo, ficando com o hemicorpo esquerdo parético por um dia aproximadamente, após o que a paresia regrediu. Há 3 meses retornaram a dispnéia e os edemas, intensificando-se progressivamente. Há um mês, caiu ao 
solo sùbitamente, sem perder a consciência, notando ter perdido a movimentação na metade esquerda do corpo. Há uma semana, agravação do edema e da dispnéia, surgindo dor no hipocôndrio direito; há 3 dias, tosse com escarro hemoptôico. Mineiro, tendo morado em casa de pau-a-pique onde havia "chupanças".

Exame clinico - Estado geral mau; dispnéia, decúbito elevado; icterícia leve da pele e das mucosas; edema dos membros inferiores; estase jugular discreta. Pulso 120 bat./min; respiração $28 \mathrm{mov} . / \mathrm{min}$; pressão arterial $100-70 \mathrm{~mm} \mathrm{Hg}$; temperatura $36,5 \circ \mathrm{C}$. Aparêlho respiratório: sinais de derrame pleural na base direita; atrito pleural acima do nível superior do derrame; alguns roncos disseminados pelo hemitórax esquerdo; poucos estertôres bolhosos nas bases. Aparêlho circulatório: choque da ponta localizado no $6^{\circ}$ intercosto, um dedo para fora da linha hemiclavicular, difuso, arrítmico; taquicardia; ritmo de galope, extrassístoles isoladas freqüentes; sôpro sistólico suave no foco mitral; hiperfonese da segunda bulha no foco pulmonar. Abdome: fígado a 4 dedos, doloroso à palpação. Sistema nervoso: consciente; em decúbito passivo; hemiplegia esquerda completa e proporcionada; tono muscular algo aumentado à esquerda, assumindo a atitıde de Wernicke-Mann. Reflexos musculares profundos vivos nos membros esquerdos; reflexos cutâneo-abdominais ausentes à esquerda; sinal de Babinski à esquerda. Clono do pé e da rótula esquerda. Automatismo no membro inferior esquerdo. Paralisia facial esquerda do tipo central; ôlho esquerdo desviado para tora em repouso, com a movimentação voluntária normal; anisocoria, com a pupila esquerda maior. No membro inferior direito, hipotonia discreta, movimentos ativos presentes, atrofia acentuada de todo o membro, com fibrilações visíveis na panturrilha, após sua percussão; reflexo aquiliano direito ausente.

Exames complementares - Exame elétrico dos membros inferiores: reações normais. Reação de Machado-Guerrero: positiva. Eletrocardiograma: Ritmo sinusal; bloqueio completo do ramo direito; alterações da condução no ramo esquerdo, com aumento da deflexão intrinsecóide em $\mathrm{V}_{5}(0,08 \mathrm{seg})$; alterações de 'T; extrassístoles ventriculares raras; R-ST com desnível minus em $\mathbf{D}_{1}$, aVL e $\mathrm{V}_{3}$ e plus em aVf e $\mathrm{V}_{4}$. Conclusões: Bloqueio $\mathrm{A}-\mathrm{V}$ parcial; bloqueio do ramo direito; bloqueio incompleto do ramo esquerdo (?); alterações primárias da onda $\mathbf{T}$.

Evolução e tratamento - Medicado com Cardiovitol, teofilina e coramina. Apesar do tratamento, as condições gerais do paciente continuaram piorando. Surgiu sudorese profusa, a pressão arterial caiu e o pulso tornou-se filiforme. Persistiram os edemas e a expectoração sangüinolenta. No $10^{\circ}$ dia de internação a dispnéia se acentuou muito, a pressão arterial era de 70-0 $\mathrm{mm} \mathrm{Hg}$ e o exame pulmonar revelava estertôres bolhosos disseminados e sôpro tubário na região interescapulovertebral direita. Óbito.

Exame necroscópico - Icterícia cutâneo-mucosa. Amigdalite lacunar crôlica. Aderências pleurais fibrosas bilaterais; hidrotórax direito; enfartes hemorrágicos, em número de três, nos lobos superior, médio e inferior do pulmão direito, restando apenas pequena área respiratória do lobo superior. Coração pesando $500 \mathrm{~g}$, rom miocardite crônica chagásica; aumento global e perda da resistência; hipertrofia ventricular discreta; fibrose intensa, especialmente do ventrículo esquerdo; adelgaçamento acentuado da ponta do ventrículo esquerdo; trombose da auriculeta direita. Congestão passiva crônica do fígado e dos rins. Amolecimento cerebral antigo nos territórios superficial e profundo da artéria cerebral média, atingindo o putâmen, o lobo da ínsula e o córtex adjacente à cissura de Sylvius do hemisfério direito; discreta dilatação ex-vacuo do ventrículo correspondente.

Comentários - Paciente de 28 anos de idade, com cardiopatia chagásica comprovada, em insuficiência cardíaca congestiva. Apresentou na evolução, além de enfarte pulmonar, dois acidentes vasculares cerebrais, o primeiro com regressão rápida e completa e o segundo, 40 dias antes do óbito. $\mathrm{O}$ exame macroscópico 
evidenciou três enfartes hemorrágicos do pulmão direito e área de amolecimento no hemisfério cerebral direito. $O$ coração, com intensa fibrose conseqüente à miocardite chagásica, mais acentuado no ventrículo esquerdo, mostrava adelgaçamento da ponta dêste ventrículo. Não foi verificada a presença de arteriosclerose nos vasos cerebrais e coronários. A trombose da auriculeta direita pode ter interferido na patogenia dos enfartes pulmonares verificados. Não foram encontrados trombos murais no coração esquerdo.

\section{COMENTARIOS}

São relatados 8 casos de moléstia de Chagas comprovada pela positividade da reaçâo de Machado-Guerrero, quatro dêles fatais (casos 2, 4, 5 e 8). Com exceção do caso 6 , que funcionalmente se enquadrava no grupo da insuficiência cardíaca de classe $I$, os restantes se apresentavam em insuficiência cardíaca congestiva; êste caso comportava o diagnóstico de cardiopatia crônica chagásica, pois, apesar de a área cardíaca ser radiològicamente normal, o eletrocardiograma revelava sinais sugestivos de comprometimento do miocárdio. Quanto à idade, um paciente (caso 3) tinha 45 anos, outro (caso 6), 39 anos e os restantes, idades variáveis entre 22 e 34 anos. Nos casos 1 e 8 houve dois acidentes vasculares cerebrais; nos demais, apenas um; em todos os casos, o acidente cerebral teve início brusco, sob forma de icto, sem pródromos. Dos casos autopsiados em um (caso 2) foi verificada a existência, no cérebro, de três áreas de amolecimento hemorrágico e nos demais havia uma zona de amolecimento isquêmico. No caso 6 , o quadro clínico, a evolução e a presença de sangue no líqüido cefalorraqueano retirado por punção suboccipital sugerem o diagnóstico de amolecimento hemorrágico. Os restantes 5 pacientes apresentaram sintomas, sinais, exame liquórico e evolução compatíveis com o quadro de acidente vascular cerebral não hemorrágico.

A hemorragia cerebral resulta, em geral, de hipertensão arterial com alterações degenerativas arteriais associadas; incidindo com maior frequiência após os 40 anos e de evolução quase sempre fatal, pode ser excluída por completo nos presentes casos. Nos casos 3 e 7, nos primeiros dias de internação, a pressão arterial se manteve um pouco acima dos limites superiores do normal; como êsses pacientes se encontravam em insuficiência cardíaca congestiva, o achado inicial de níveis de pressão arterial elevados era devido, provàvelmente, à assim chamada "hipertensão de estase", caindo a pressão aos níveis habituais após a melhora das condições cardíacas. No entanto, com relação ao paciente A. J. S. (caso 3), de 45 anos de idade, não se pôde excluir a possibilidade da associação de hipertensão essencial benigna à doença de Chagas.

Dentre as causas de hemorragia cerebral, é necessário analisar a rotura de aneurisma intracraniano que é, com frequência, a etiologia dos acidentes vasculares cerebrais hemorrágicos em indivíduos jovens. Os aneurismas habitualmente se localizam na base ou nas faces laterais do cérebro, mas podem ser mais profundos; pela rotura de um aneurisma profun- 
damente situado, o sangue pode atravessar o tecido cerebral e alcançar o sistema ventricular; outras vêzes, porém, não o atinge, permanecendo o líqüido cefalorraqueano com aspecto normal. No caso 6 , a história de cefaléias repetidas há 3 anos, com maior intensidade na região frontal direita, sugeria a existência de aneurisma intracraniano que, pela rotura, tivesse acarretado a hemiplegia esquerda; apesar da carótido-angiografia direita não haver mostrado qualquer anormalidade morfológica nos vasos intracranianos, a hipótese permanece viável.

A trombose cerebral é, de modo geral, um quadro menos dramático que a hemorragia; seu início é gradual e a sintomatologia é progressiva, com sintomas prodrômicos. Entre suas causas sobressai, pela frequiência, a arteriosclerose. No caso 3 , a idade do paciente (45 anos) não permite afastar a possibilidade da existência de arteriosclerose, associada ou não a hipertensão arterial, embora não se tenha encontrado qualquer evidência de esclerose vascular; o acidente cerebral poderia, nesse caso, ter sido conseqüência de trombose, embora se tenha manifestado sob a forma de icto, sem pródromos. O encontro, no exame necroscópico do caso 2, de arteriosclerose cerebral do tipo difuso, constituiu surprêsa, não só pela idade da paciente (33 anos) -- idade na qual não é habitual a existência dessa alteração vascular - como pelo fato de ser isolada, não se encontrando evidências dêsse processo degenerativo em qualquer outro órgão. A sífilis pode ser excluída nos presentes casos pela negatividade das reações sorológicas e dos exames de líquido cefalorraqueano. A anemia falciforme, doença que ocorre em indivíduos pretos ou pardos, se caracteriza pela produção de tromboses nos diversos órgãos, podendo, pois, acarretar trombose cerebral; dos pacientes relacionados neste trabalho, 3 eram pretos e 3 , pardos. Em 4 dêles foi feita a prova de falcização, com resultado negativo; nos casos 1 e 2 essa prova não foi realizada, mas os hemogramas e o quadro clínico não sugeriam a presença de anemia falciforme.

A embolia cerebral é a causa mais freqüente de acidentes vasculares cerebrais não hemorrágicos nos indivíduos jovens, iniciando-se a sintomatologia bruscamente, sem manifestações premonitórias. $O$ diagnóstico só pode ser feito em presença de uma fonte definida de êmbolos. A fibrilação auricular, que constitui condição extremamente favorecedora da formação de trombos intra-auriculares, não foi verificada em nenhum dos presentes casos. Essa arritmia é raramente observada na cardiopatia chagásica: assim, E. Chagas ${ }^{2}$, analisando as alterações eletrocardiográficas em 35 casos dessa cardiopatia, encontrou-a apenas uma vez; Ramos e col. ${ }^{5}$ verificaram-na em dois dentre 72 casos. A cardiopatia reumatismal e a endocardite bacteriana subaguda puderam ser fàcilmente afastadas nos 8 casos apresentados neste trabalho. Das cardiopatias congênitas, apenas a dextrocardia foi verificada em um caso e é sabido que esta anomalia comporta bom prognóstico, não favorecendo o aparecimento de complicações. Nenhum dos casos apresentava sinais clínicos de comunicações intercavitárias. 
Resta a hipótese de embolia cerebral a partir de trombos murais cardíacos. E' conhecida a freqüência da trombose mural na miocardite chagásica. Tem sido chamada também a atenção, ùltimamente, para o fenômeno da fibrose com adelgaçamento da ponta do ventrículo esquerdo, já descrito pelo próprio Carlos Chagas. A êsse respeito, escreve Laranja ${ }^{4}$ : " $E$ ' de regra encontrar-se sôbre a superfície endocárdica, em correspondência com essas áreas de adelgaçamento da ponta do ventrículo esquuerdo, trombos murais, em diferentes fases de organização. Na série de 38 casos de cardiopatia crônica chagásica até o momento autopsiados em Bambuí, encontramos trombose mural na ponta do ventrículo esquerdo em 12 dêles, havendo, em alguns casos, também trombose na aurícula direita. Tais fenômenos, decorrentes por certo da endocardite parietal crônica, conforme assinalou Magarinos Tôrres, ocasionando complicações embólicas, especialmente nos pulmões, parecem ser bastante comuns na evolução dos doentes com cardiopatia crônica chagásica, e não raro constituem a causa imediata da morte. Muito raramente o adelgaçamento da parede do coração em correspondência com trombose da ponta do ventrículo esquerdo chega a formar verdadeiro aneurisma da ponta do coração. Não sabemos se essas áreas de fibrose localizada, com destruição local quase completa das fi. bras musculares, na miocardite crônica chagásica, não conseqüência de distúrbios circulatórios com isquemia local. Áreas de adelgaçamento da parede cardíaca foram assinaladas por Chagas, que descreveu a espessura das paredes ventriculares em certas zonas como comparável à de uma fôlha de papel, tendo encontrado, à autópsia de um indivíduo que tivera morte súbita, rotura da parede do ventrículo direito". A êsse adelgaçamento da ponta corresponde um quadro característico no eletrocardiogra. ma. Assim, em aVr encontra-se um $\mathrm{R}$ tardio, sem aumento da duração. Mais características são as unipolares do precórdio, mostrando diminuição de $R$ nas precordiais esquerdas, às vêzes apenas em $V_{3}$ e $V_{4}$, exprimindo o potencial diminuído da zona adelgaçada. Devido a êsse quadro eletrocardiográfico, a lesão descrita tem sido denominada "enfarte da ponta". Carvalhal ${ }^{1}$, em 30 casos necropsiados de cardiopatia chagásica, encontrou, para as tromboses murais e para o "enfarte de ponta", a freqüência conjunta de aproximadamente $50 \%$, verificando que, na superfície endocárdica da zona adelgaçada, existia sempre trombose, macro ou microscópica. Ainda na experiência de Carvalhal ${ }^{1}$, os órgãos mais atingidos por embolias na cardiopatia chagásica são os pulmôes. A embolia pulmonar, determinando quase sempre enfarte hemorrágico, seria freqüentíssima nos chagásicos que falecem em insuficiência cardíaca. A seguir, na ordem de freqüência, seguem-se o baço e os rins, onde as embolias acarretam enfartes anêmicos. Enfartes pulmonares ocorreram em 6 dos casos relacionados neste trabalho, em geral precedendo de poucos dias o acidente vascular cerebral.

No primeiro caso necropsiado (caso 2) foram encontrados enfartes anêmicos no pâncreas e no rim direito; na falta de outra causa, podemos 
afirmar que êsses enfartes foram conseqüentes a êmbolos destacados do grande trombo mural encontrado no ventrículo esquerdo; a trombose da aorta abdominal e das ilíacas também parece ter sido determinada inicialmente por uma embolia a partir da mesma fonte, com a superposição ulterior de alterações trombóticas; quanto aos amolecimentos cerebrais hemorrágicos, nada se pode afirmar quanto à sua etiologia, pois o achado de arteriosclerose cerebral não permite a diferenciação entre a trombose por essa causa e a embolia a partir do trombo mural. No caso 4, o exame necroscópico mostrou a presença de enfartes em ambos os rins e no pulmão; êstes podem ser explicados, também, como conseqüentes aos trombos murais encontrados no ventrículo esquerdo. A encefalomalácia, pela oclusão da artéria cerebral média junto aos pontos de emissão dos ranos profundos. A oclusão arterial já se apresentava organizada, não se podendo diferençar mais de processo originàriamente trombótico; é necessário lembrar, porém, que o óbito ocorreu 10 meses após o acidente cerebral, tendo havido tempo suficiènte para a organização do material, trombótico ou embólico. A presença de trombos murais no ventrículo esquerdo e a inexistência de outras alterações vasculares encefálicas é que falam a favor da etiologia embólica dessa oclusão. No caso 5 , além da presença de trombo mural da ponta do ventrículo esquerdo não foram verificados enfartes e não foi descrita arteriosclerose, apresentando-se as artérias da base do encéfalo com caracteres normais; embora não tivessem sido efetuados cortes do encéfalo para o estudo da sede da oclusão vascular que determinou o acidente cerebral, não havia sinais externos sugestivos de outras etiologias. $O$ exame anátomo-patológico do caso 8 mostrou a presença de três enfartes no pulmão direito, cuja etiopatogenia, na ausência de tromboflebite nos membros inferiores, é explicada pela trombose da auriculeta direita; no hemisfério cerebral direito havia uma zona de amolecimento, não sendo encontrado qualquer dos fatôres etiológicos conhecidos como causadores de acidentes vasculares cerebrais; apesar da existência de adelgaçamento da ponta, não foram encontrados trombos na metade esquerda do coração; êsse fato, porém, não invalida a hipótese de embolia cerebral a partir do trombo cardíaco, pois é conhecida a possibilidade da formação de trombos murais pouco aderentes, sobretudo nas auriculetas, que se desprendem inteiramente, sem deixar fragmentos presos ao endocárdio.

A demonstração da natureza embólica do acidente vascular cerebral na cardiopatia chagásica do ponto de vista necroscópico deveria preencher as três condições seguintes: 1 - encontro de amolecimento cerebral; 2 - verificação de trombose mural nas câmaras cardíacas esquerdas; 3 existência de qualquer dos fatôres etiológicos conhecidos de acidente vascular cerebral. Nos casos 2 e 8 tais condições não são preenchidas, pois o caso 2 preenche as duas primeiras, mas não a terceira; por sua vez, o caso 8 preenche a primeira e a terceira, mas não a segunda. Nos casos 4 e 5 são as três condições preenchidas, levando-se em conta, em relação 
àquele, a inexistência de achados exteriores sugestivos de outras etiologias no encéfalo, fixado para estudo ulterior.

Quanto aos casos em evolução favorável, no caso 3 não se pôde excluir a trombose cerebral decorrente de hipertensão ou de arteriosclerose e, no caso 6 , a hipótese de hemorragia cerebral por rotura de aneurisma não pôde ser afastada. Nos dois casos restantes (casos 1 e 7 ) não se conseguiu apurar a existência de qualquer dos fatôres etiológicos conhecidos como determinantes de acidentes vasculares cerebrais.

Assim, apesar de dois dos casos necropsiados não terem possibilitado plena comprovação, parece que, nos 8 pacientes, os acidentes cerebrais tenham decorrido de embolias a partir de trombos murais cardíacos. Lembrando que em 7 dos casos os acidentes vasculares cerebrais foram observados em prazo de oito meses, é necessário chamar a atenção dos clínicos e neurologistas para a pesquisa da moléstia de Chagas em todos os pacientes com acidente vascular cerebral cuja etiologia não puder ser explicada pelos fatôres habituais.

\section{RESUMO}

Os autores apresentam oito casos de cardiopatia crônica chagásica, comprovada pela reação de Machado-Guerrero, em cuja evolução ocorreram acidentes vasculares cerebrais. Discutem a etiologia dêsses acidentes, afastando os fatôres etiológicos conhecidos e formulando a hipótese de embolia cerebral a partir de trombose mural cardíaca. Quatro casos foram fatais, tendo sido necropsiados. Em dois dêles os achados anátomo-patológicos vieram comprovar a hipótese, enquanto, dos dois restantes, em um havia concomitantemente arteriosclerose cerebral difusa e no outro verificou-se amolecimento cerebral, na ausência de qualquer dos fatôres etiológicos conhecidos, mas não havia trombose nas cavidades esquerdas do coração; é lembrada a possibilidade de trombo mural fracamente aderido ao endocárdio, que se tivesse desprendido in totum. Embora não tivessem conseguido a comprovação de sua hipótese, os autores são de opinião que êste foi o mecanismo patogênico nos 8 casos apresentados e chamam a atenção para a doença de Chagas como fator etiológico da embolia cerebral.

\section{SUMMARY}

The authors report eight cases of Chagas' heart disease, proved by positive Machado-Guerrero reaction, in whose evolution there occurred cerebrovascular accidents. They discuss the etiology of these accidents, excluding the common etiological factors and set forth the hypothesis of cerebral embolism from cardiac mural trombosis. Death occurred in four cases, which were submitted to post mortem examination; in two cases the 
necroscopic findings support the hypothesis. In one of the other two it was found mural thrombosis in the left ventricle and three cerebral hemorrhagic softenings, but there was simultaneously diffuse cerebral arteriosclerosis and in the other there was a cerebral softening and none of the habitual etiologic factors was found, but there was no thrombosis in the left heart; the possibility is reminded of a weakly adherent to endocardium mural thrombus, which loosed completely. The embolic nature of these cerebrovascular accidents is supported by the authors in the eight cases reported and they emphasize Chagas' disease as an etiolcgical factor of cerebral embolism.

\section{BIBLIOGRAFIA}

1. Carvalhal, S. - Comunicação pessoal. 2. Chagas, E. - Estudo eletrocardiográfico na forma cardíaca da tripanossomíase americana. Fôlha Méd., 11: 97-99; 113-115; 159-160; 1930. 3. Dias, E., Laranja, F. S. e Nóbrega, G Doença de Chagas. Mem. Inst. Oswaldo Cruz, 43:495-582, 1945. 4. Laranja, F. S. - Evolução dos conhecimentos sôbre a cardiopatia de Chagas. Revisão crítica da literatura. Mem. Inst. Oswaldo Cruz, 47:605-669, 1949. 5. Ramos, J., Pedreira de Freitas, J. L. e Borges, S. - Moléstia de Chagas. Estudo clínico e epidemiológico. Arq. Bras. Cardiol., 2:111-162, 1949.

Hospital das Clinicas da Fac. Med. da Univ. de São Paulo. 